\title{
Configuring Information Systems and Work Practices for Each Other: What
} Competences Are Needed Locally?

\author{
Hertzum, Morten; Simonsen, Jesper
}

Published in:

International Journal of Human-Computer Studies

DOI:

10.1016/j.ijhcs.2018.10.006

Publication date:

2019

Document version

Peer reviewed version

Citation for published version (APA):

Hertzum, M., \& Simonsen, J. (2019). Configuring Information Systems and Work Practices for Each Other: What Competences Are Needed Locally? International Journal of Human-Computer Studies, 122, 242-255. https://doi.org/10.1016/j.ijhcs.2018.10.006 


\title{
Configuring Information Systems and Work Practices for Each Other: What Competences Are Needed Locally?
}

\author{
Morten Hertzum \\ University of Copenhagen, Njalsgade 76, Bldg 4A, Copenhagen, Denmark, hertzum@hum.ku.dk \\ Jesper Simonsen \\ Roskilde University, Universitetsvej 1, Bldg 8.2, Roskilde, Denmark, simonsen@ruc.dk
}

Abstract. Previously technical design was the realm of software engineers; now it is increasingly completed by users who configure systems after go-live. To exploit the possibilities afforded by systems the users also adapt their practices in response to their systems. The process of configuring systems and practices for each other is rich in local particulars, protracted in time, and demanding in competences. In this study we catalog the competences needed locally to accomplish change by configuring systems and practices for each other. The empirical context for the study is a project about reducing hospital patients' fasting time before surgical operations. We identify and describe 21 competences that must be present locally. They form seven types: managing projects, understanding practice, understanding technology, preparing change, making change, assessing change, and personal traits. The project participants display the competence types with varying frequencies, thereby for example indicating that understanding practice is a larger issue than understanding technology. Preparing and making change are, probably, the two competence types that are most thinly spread locally. The catalog of the competences needed locally to configure systems and practices for each other after go-live can inform decisions about project staffing, competence building, and - more generally - curriculum development.

Keywords: competences, sociotechnical change, systems implementation, design in use, configurability, user-driven design

\section{Introduction}

To be of benefit to users information systems must be adapted to work practices, and vice versa (e.g., Bikson \& Eveland, 1998; Carroll et al., 1991; Leonard-Barton, 1988; Markus, 2004). Systems must be adapted to work practices to support local needs and heed local circumstances; work practices must be adapted to systems to exploit the possibilities afforded by the systems. This mutual adaptation is often a two-stage process of organizational implementation followed by local adoption (Gallivan, 2001). Because information systems are increasingly configurable, the possibilities for adapting them to local needs and circumstances are not confined to the first stage but continue into local adoption. Thereby, design - in terms of the configuration of systems and practices - increasingly becomes a local affair performed by local actors. In this study we investigate the competences needed locally to accomplish change by configuring systems and practices for each other.

Before systems became configurable technical design was the realm of software engineers, who had the competences to work with the technology. In contrast the users could adapt their ways of working in response to systems but they normally had neither the technical competence necessary to change the systems, nor access to facilities for making such changes. With the introduction of configurable systems technical design is increasingly completed by the users after the system has gone live. This 
continuation of design into use may be the result of a deliberate design-in-use process (Torkilsheyggi \& Hertzum, 2017) or it may emerge in unplanned, improvisational ways (Orlikowski, 1996). In this study we focus on deliberate efforts. Importantly, the present study differs from research on user participation in systems development (e.g., Kujala, 2003; McKeen \& Guimaraes, 1997), in which users are involved prior to go-live in a process driven by others. Empirically, we investigate how an electronic whiteboard already in use at a hospital was configured for reducing the length of time for which the patients were fasting before surgical operations. Shorter fasting times would benefit the patients but required changes in the preoperative coordination. The studied project lasted a year and was conducted by local healthcare professionals in collaboration with the authors. By analyzing the content of the project meetings we catalog the competences displayed by the project participants. These competences were needed locally to configure the whiteboard for showing the patients' fasting time and to devise the associated new ways of working.

Competences are a debated issue (Chouhan \& Srivastava, 2014; Hoffmann, 1999). Previous research has cataloged the competences needed by information systems professionals (e.g., Topi et al., 2017) but has not similarly investigated the competences needed locally during design in use. For example, Dittrich et al. (2002) flagged the need for supporting design-in-use processes with technical competences, which were not present locally. Torkilsheyggi and Hertzum (2017) flagged a need for organizationally powerful allies to make change happen, thereby suggesting that local actors need a competence in making change happen and often struggle in this regard. While important, these designin-use studies merely identify single competences. In this study we ask a primary and a supplementary research question:

- What competences are needed locally to accomplish change by configuring information systems and work practices for each other after go-live? The answer to this question consists of 21 competences arranged into seven types.

- How are these competences distributed across participants and over time? The answer to this supplementary question consists of the distribution of the seven competence types across the three groups of project participants and across the first and second half of the project.

We discuss the extent to which the identified competences are present locally, the challenges in accomplishing change locally, and the implications of this study.

\section{Background: What is a competence?}

Competence is a multi-faceted concept. It has been construed as "minimum standards of competent performance" (Strebler et al., 1997, p. 3), as "a dimension of overt, manifest behaviour that allows a person to perform competently" (Woodruffe, 1993, p. 29), and as "the underlying attributes of a person such as their knowledge, skills or abilities" (Hoffmann, 1999, p. 276). These three ways of construing competence (performance standard, overt behavior, and underlying attributes) exemplify the variety of agendas associated with the concept, but they also connect and interrelate. An important connection is the shared premise that competences are carried by individuals but performed and assessed in ways that are shaped by situations and social circumstances (Mitchelmore \& Rowley, 2010). Thus, the same underlying attributes lead to different overt behaviors in different situations, the same overt behaviors meet performance standards in only some situations, and the same performance standards require different underlying attributes in different situations.

In Bloom's taxonomy (Bloom et al., 1956) competences form a hierarchy in which each simpler competence is prerequisite to mastery of the next more complex competence. Ordered from simple to complex the six competence categories in the taxonomy are: knowledge, comprehension, application, analysis, synthesis, and evaluation. Bloom's taxonomy has been very influential in training and education. For example, the European Qualifications Framework defines competence hierarchically in terms of knowledge, skills, and abilities: "the ability to use knowledge, skills and personal, social and/or methodological abilities, in work or study situations and in professional and 
personal development" (EU, 2015, p. 67). Construing competences as underlying attributes implies a focus on the simplest competence category: knowledge. Krathwohl (2002) criticized curricular objectives, and thereby exams, for near exclusively adopting such a focus. In contrast, construing competences as overt behavior implies a focus on skills and requires mastery of more complex competence categories such as application, analysis, and synthesis. Similarly, construing competences as performance standards implies a focus on the complex categories, which subsume the simpler ones and thereby require mastery of multiple levels of competences.

In their catalog of the competences that must be possessed by professionals with a master in information systems Topi et al. (2017) distinguish between information-systems competences, individual foundational competences, and domain competences. The nine areas of informationsystems competences are distinctive to a master in information systems. Of particular relevance to the present study the area of innovation, organizational change, and entrepreneurship covers "the ability to recognize and exploit the potential afforded by current and upcoming technologies to address existing and new business opportunities" (p. 18). This area includes the competences required to understand and intervene in organizational activities with the objective of using technology to improve the way those activities are structured and performed. However, Topi et al. (2017) do not mention support for local design-in-use activities after go-live. Individual foundational competences are those competences necessary for all knowledge professionals in a variety of professions. We presume they will also be useful to local actors involved in design in use. They include competences in collaboration, communication, critical thinking, and problem solving. Several of these competences resemble personal traits. Finally, domain competences concern the domain of practice (e.g., business, government, healthcare) in which the information-systems professional will work. These competences are left largely unspecified by Topi et al. (2017). For local actors the domain competences will dominate, while information-systems competences will typically be sparse.

\section{Related work}

Lieberman et al. (2006) stress the importance of making systems configurable. In the following we presume such configurability and focus, instead, on what is required from the actors who configure systems and practices. We start by reviewing work that approaches configuration as design in use. While this work addresses local configuration directly, it tends to talk indirectly, if at all, about competences. Therefore, we proceed to describe work in the broader area of the diffusion of innovations. This work identifies roles that embody central competences but its focus on innovation in general bypasses the particulars of diffusing information systems. To return to information systems we end this section by briefly looking at work on what is required from user participants in systems development.

\subsection{Configuration as design in use}

The two-stage process of organizational implementation followed by local adoption divides the introduction of information systems into a managerial decision process that makes the system available within the organization and a local assimilation process that incorporates the system in the organization (Gallivan, 2001). With configurable systems the local assimilation has increasingly become a design process. This process is known as design in use (e.g., Bjögvinsson et al., 2012; Folcher, 2003; Henderson \& Kyng, 1991) to distinguish it from the design that precedes the introduction of a system in the use organization. For groupware the local assimilation has long been recognized as a separate design-in-use process by the groups that adopt the groupware system (e.g., Mark \& Poltrock, 2004; Okamura et al., 1995). For organization-wide systems it may be more difficult to tell design in use from design before use, especially if the design-in-use process is an organizationally planned extension of the design-before-use process.

The differences between design before use and design in use concern, at least, the timing, object, process, and conditions for local participation. First, the timing is different because the shift from 
before to after the users start using the system in their work introduces a longer temporal perspective. While systems development prior to use happens in temporary project organizations, configuration after go-live relates to organizational change programs, which are about "continuous improvement" (Markus, 2004, p. 11). Second, the object of design shifts from software toward services because configuration is driven by users, and their key concern is to support their work. Such support requires the assemblage of a working configuration that involves technical components, work procedures, intermediate products, and enrolled colleagues. The whole assemblage must be configured, not just the technology (Balka \& Wagner, 2006). Third, the process differs from that of design before use because the users "live with" (Aanestad et al., 2017) the system in the sense that they use it for actual work on an ongoing basis. The integration of configuration in use provides possibilities for moving smoothly and quickly between using a system for work, grappling with the problems of applying the system, adjusting the system or its use, and evaluating the outcome of the adjustments (Hartswood et al., 2002). Finally, the conditions for the users' participation change because they themselves configure the system and practices rather than serve as informants in a process driven by others (Kujala, 2003). To be able to configure by themselves the users need a broader set of competences. This need is accentuated by the frequent absence of support from professional designers (Dittrich et al., 2002).

Previous work on design in use has mostly addressed competences indirectly by discussing the kinds of support necessary for design in use to succeed. Multiple studies identify a need for local intermediaries who are skilled in configuring systems and tasked with supporting design in use (e.g., Dittrich et al., 2002; Hartswood et al., 2002). For example, Mackay (1990) identifies a group who acted as translators between highly technical staff and the rest of the organization, thereby creating system customizations relevant to their colleagues' needs. The basic premise of these studies is that design in use requires knowledge about the work domain and about design; the users are assumed to have the former but to need support with regard to the latter. Knowledge about design involves technical competences as well as design-process competences. Other studies identify a need for allies with the organizational power to ensure that the configured solution is adopted in the organization (e.g., Okamura et al., 1995; Torkilsheyggi \& Hertzum, 2017). The basic premise of these studies is that the ability to devise the configured solution does not guarantee the ability to see it through to dissemination and uptake. In yet another study Kanstrup and Bertelsen (2006) investigate how a group of IT supporters took on a design-in-use role. To succeed in this role the IT supporters needed to be (a) emphatic toward the system to see its possibilities and work toward realizing them in use, (b) collaborative to make their work with the system visible and thereby engage the users, and (c) communicative and reflective to connect with the broader use context and remove prejudices. This points to the importance of much softer competences than technical knowhow. Finally, studies provide evidence of both planned and emergent change and, thereby, recognize competences in seeing planned change through to completion as well as in detecting emergent change and seizing the opportunities it provides (e.g., Orlikowski \& Hofman, 1997; Simonsen \& Hertzum, 2008).

\subsection{Configuration as diffusion of innovations}

The abovementioned ability to see the configured solution through to dissemination and uptake is about the diffusion of innovations. Research on the diffusion of innovations is a broad area with no specific focus on information systems. Because many innovations are less configurable than information systems this research tends to under-recognize design in use (reinvention in diffusion-ofinnovation terms). However, it identifies three roles that embody competences central to the dissemination and uptake of systems (Rogers, 2003):

First, innovators play the important role of launching new ideas in an organization. To fulfil this role they are first and foremost venturesome. In addition, they are able to understand and apply complex technology, to cope with uncertainty, and to absorb - psychologically and otherwise - the setbacks of ideas that prove unsuccessful. While innovators have an important role in the diffusion of innovations, they may have a peripheral position in their organization. 
Second, opinion leaders are organization members with the ability to influence their colleagues' attitudes or behavior. Opinion leadership is earned and maintained through technical competence, social accessibility, and conformity to organizational norms. Opinion leaders exert their influence informally, rather than through a formal position. They are often among the early adopters of new innovations and know that to maintain their influence they must make judicious innovation decisions.

Third, change agents are organization externals, such as consultants, who seek to influence the innovation decisions of an organization in the direction deemed desirable by their client. Change agency involves developing a need for change, diagnosing problems, creating an intent to change, translating the intent into action, stabilizing adoption, and preventing discontinuance.

A role similar to that of opinion leader is the champion, who may have formal power in the organization but must possess interpersonal and negotiating skills in working with other people. Champions are charismatic individuals who throw their weight behind an innovation to overcome the indifference or resistance that the innovation may provoke (Rogers, 2003). The importance of champions and opinion leaders has been emphasized by Schön $(1963$, p. 84) who states that "the new idea either finds a champion or dies". It appears that change agents' status as organization externals makes them more effective at stimulating change by shaping new possibilities than at implementing it (Ginsberg \& Abrahamson, 1991). This differential ability restricts their role in making change happen for the reason that they lack the organizational position necessary to counteract partial use that blocks implementation. Reversing the argument, local users may be too entwined in their current ways of working to see radically new possibilities but, simply by being local, better able to implement the possibilities they do see. Relatedly, Okamura et al. (1995) conclude that design-in-use processes are better supported by people who are themselves users of the system. However, their argument is not that local users have positions that grant them power but that being users makes them better able to appreciate user concerns and more sensitive to user feedback.

\subsection{User participation in systems development}

While the research on user participation in systems development is mostly about design before use, we want to mention two issues that reach into the configuration of systems and practices after go-live. First, Kensing and Munk-Madsen (1993) emphasize that user-developer communication must provide knowledge about the users' present work, the technological options, and the new system. For each area both abstract and concrete knowledge is needed. Knowledge about the new system must for example include visions and design proposals (abstract) as well as experience with early versions of the new system (concrete). The six resulting knowledge areas have also been identified in the implementation and configuration of enterprise resource planning (ERP) systems by users and ERP consultants (Pries-Heje \& Dittrich, 2009). Thus, competences in these six areas appear important also during configuration. Second, Rasmussen et al. (2011) find that the selection of users for participation in systems development projects favors persons who can contribute to the progress of the projects over persons who are representative of the full range of users. A highly valued contribution from participating users is "the ability to advocate a vision for the system and champion its organizational implementation" (Rasmussen et al., 2011, p. 176). This ability explicitly reaches beyond go-live and, thereby, into any configuration activities. To succeed in configuring systems and practices local users may, however, also need the deemphasized ability to represent their colleagues in a balanced manner. Misrepresenting the full range of users incurs the risks of failing to configure systems and practices for local needs and of stirring resistance from the users whose needs are disregarded.

\section{Method}

Since 2005 the authors have collaborated with Region Zealand, one of the five healthcare regions in Denmark, about the configuration, design in use, and evaluation of healthcare information systems. This collaboration followed a participatory design approach with the authors as active contributors to local initiatives. Gradually, it became a recognized end in the collaboration to provide the healthcare 
region, in practice local clinicians, with competences that would enable them to take over the authors' role in the collaboration. Our interest in cataloging the competences needed locally to accomplish change with information systems emerged from this recognition.

The present study was conducted at a medium-sized hospital in Region Zealand after the study had been approved by the region and by hospital management. The studied hospital had 250 beds and its 1,140 employees served an area of approximately 150,000 citizens.

\subsection{Setting: the fasting-time project}

Following the successful introduction of an electronic whiteboard in the emergency department (Rasmussen et al., 2010), the whiteboard was introduced on all departments in the hospital in December 2012. The whiteboard gave one row of information about each patient. It was permanently available on large, wall-mounted displays (see Figure 1) and available on demand on any computer. While the fields of information displayed about each patient could be tailored to the needs of the individual department, frequent fields of information included time of arrival, first name, room, responsible physician, status of laboratory tests, and next stop. By introducing the whiteboard in all departments the hospital aimed to make it a means of interdepartmental coordination. An early example of such interdepartmental coordination was the field 'next stop', which specified the department to which the patient was scheduled for transfer. The present study concerned the use of the whiteboard for shortening patients' preoperative fasting. Achieving this effect would be an improvement in the interdepartmental coordination of the operations and, in addition, beneficial to patient health (e.g., Lambert \& Carey, 2016; Nygren, 2006; Pimenta \& de Aguilar-Nascimento, 2014).

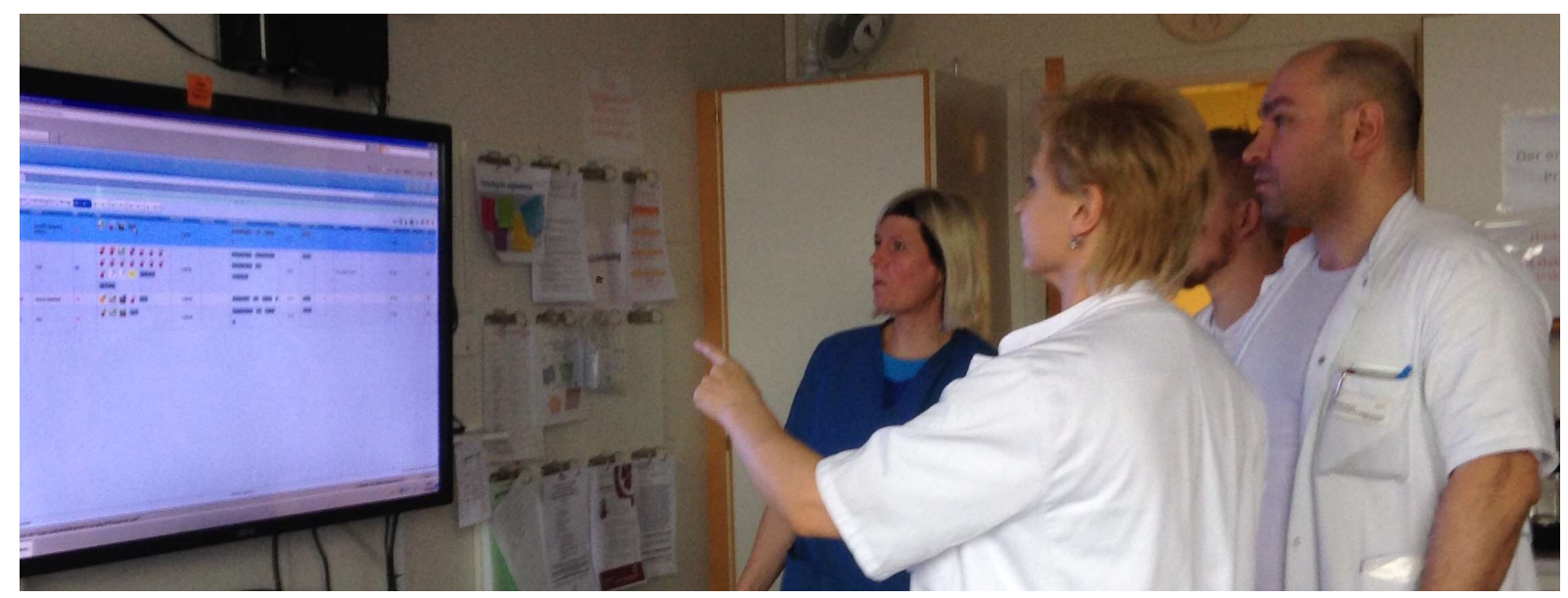

Figure 1. The electronic whiteboard at the operating ward

Fasting was mandatory before operations to minimize vomiting during anesthesia and, thereby, reduce the risk of pulmonary aspiration. Following established practice guidelines the patients were not allowed to eat for six hours before surgery and to drink clear liquids for two hours before surgery (American Society of Anesthesiologists, 2011). However, the patients at the studied hospital were often fasting for considerably more than six hours. One reason for longer fasting times was that while the operation date was set in advance, the time of day was often not decided until the morning of the day of the operation. This practice increased the surgeons' possibilities for incorporating acute operations in their daily schedule but also meant that all the day's patients had to start fasting sufficiently early to be ready for operation in the morning even though most of them would not be operated until later in the day.

The decision to try to reduce the preoperative fasting time was made during a series of workshops in the Fall of 2014. Clinicians from different staff groups and departments attended the workshops, which 
were arranged to specify what the clinicians wanted to achieve by introducing the whiteboard in their departments. To make the specifications operational they were formulated in terms of effects that were both desirable and measurable. At the last workshop the clinicians prioritized the effects they had specified; the effect of reducing the patients' preoperative fasting time received top priority. In continuation of the workshops a project was established to realize the fasting-time effect. The project group consisted of three healthcare professionals from the hospital, the two authors of the present study, and a research assistant. The three healthcare professionals were super users of the whiteboard; they were a nurse from the operating ward and a secretary from each of the two surgical departments. In addition, representatives of management and physicians participated in three of the project meetings to discuss selected issues. These representatives numbered 1,4 , and 2 persons at the three meetings.

\subsection{Data: the project meetings}

The project group met once every two weeks during most of 2015, for a total of 17 meetings (36 hours). Following the effects-driven approach described by Hertzum and Simonsen (2011), the project consisted of effects specification, effects realization, and effects assessment. While the fasting-time effect had been specified ahead of the meetings, the meetings covered the phases of effects realization (February-May), effects assessment (May-September), and another phase of effects realization (September-December). At the meetings the activities involved in realizing and assessing the fastingtime effect were identified, discussed, delegated, and followed-up on. The activities performed inbetween the meetings were reported and discussed at the meetings, which in that way also contained a record of these activities. With the permission of all group members, the meetings were audiorecorded. These audio-recordings constituted the data for this study. We contend that the content of the meetings is a rich source of insights about the competences displayed by the participants in performing the project.

The first phase of effects realization involved configuring the whiteboard to show the patients' fasting time, devising the procedure for recording the fasting times on the whiteboard, and seeking to implement the recording and use of the fasting-time information in the clinicians' practices. The phase of effects assessment involved validating the fasting-time information extracted from the whiteboard and reflecting on the competing priorities that caused the long average fasting times. Over the threemonth assessment period the fasting times were an average of 13.3 hours. The second phase of effects realization was exclusively about implementing the recording and use of the fasting-time information in the clinicians' practices. To create a recurring occasion for using the fasting-time information in the preoperative coordination a daily timeout was introduced at the hospital. The timeout was a brief cross-departmental meeting held at the whiteboard for the purpose of prioritizing the patients scheduled for operation. Our engagement in the fasting-time project ended in December 2015 after the second phase of effects realization. The project was closed in February 2016 without obtaining a shortening of the fasting times. The principal reason for closing the project was a decision to replace the whiteboard with a new region-wide electronic patient record.

\subsection{Data analysis}

We coded the data in a ground-up manner that involved five steps (Figure 2). We chose a ground-up analysis because previous studies of local configuration activities have merely identified single competences and, thus, not provided a framework that could guide our coding. Based on our knowledge from participating in the meetings, the audio-recordings of the ten most important meetings were selected and transcribed verbatim. The transcripts contained the participants' oral contributions to the discussions at the meetings, that is, their overt behavior. Through their overt behavior the participants displayed their ability to perform and act competently in relation to the fasting-time project. The transcripts also included the initials of the speaker.

For the first step we selected two of the transcripts. Both authors individually read these transcripts line by line and made annotations of all instances of competences displayed by the participants. We 
included competences at all six levels of Bloom's taxonomy (Bloom et al., 1956), but because the transcripts gave the participants' overt behavior most annotations concerned the middle and upper levels of the taxonomy. In particular, the simplest level - the knowledge level - was mostly subsumed in more complex competences. As an example, one of the annotations read "Understanding the importance of aligning the introduction of the fasting-time columns with the hospital-wide restructuring of the whiteboards". This annotation identified the comprehension-level competence of improving the chances that a project activity would succeed by aligning it with other activities at the hospital. After annotating the two transcripts the authors met for grouping the annotations through a process of affinity diagramming (Beyer \& Holtzblatt, 1998). The affinity diagramming led to an initial set of groups and also served to create a shared understanding of what we should be sensitive to in reading the transcripts.

- Both authors individually annotated 2 transcripts

- Authors met and affinity diagrammed the annotations

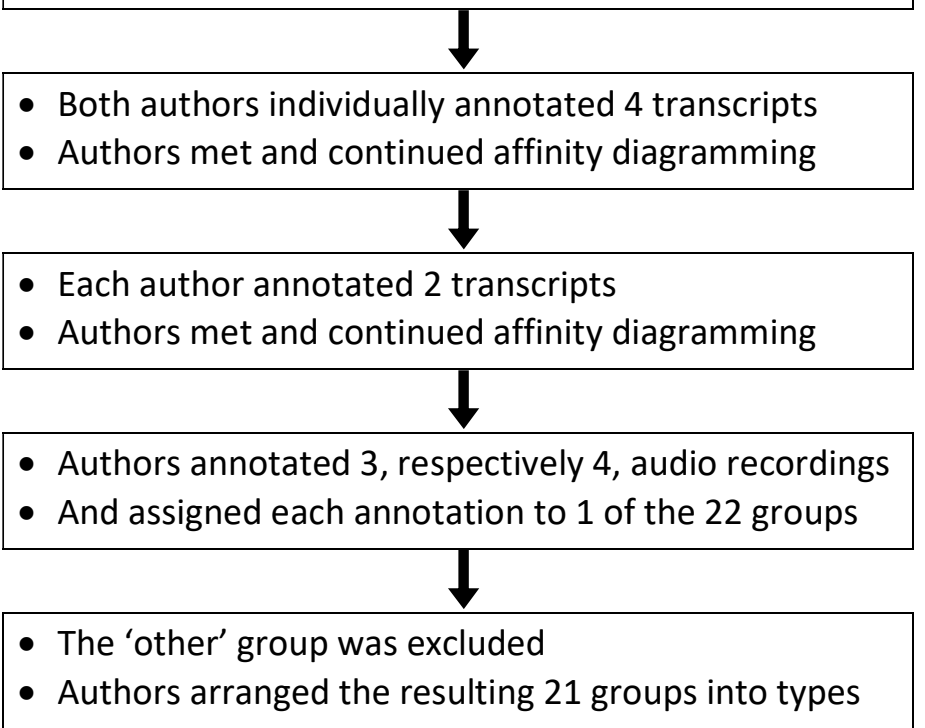

Input: 2 transcribed meetings

Output: 18 competence groups

Input: 4 transcribed meetings

Output: 21 competence groups ( 3 new)

Input: 4 transcribed meetings

Output: 22 competence groups (1 new)

Input: 7 audio-recorded meetings

Output: 22 competence groups (no new)

Input: 22 competence groups

Output: 7 competence types

Figure 2. The five-step process of data analysis

In the second step, both authors individually read and annotated four more transcripts. We then met and continued the process of affinity diagramming. While this second round of affinity diagramming added many new instances to the existing groups, it only led to the creation of three new groups. One of these new groups was "Specification of measurements". On the basis of this indication of theoretical saturation (Glaser \& Strauss, 1967) we decided that it was no longer necessary that both authors coded each transcript. In the third step, each author annotated two of the remaining transcripts and we met for a final round of affinity diagramming. Only one new group emerged, "Modeling interventions". This way the affinity diagramming resulted in 22 groups created from 480 annotations. In the fourth step the authors coded the seven meetings that had not been transcribed. This coding was done by listening through the audio-recordings, identifying the instances of competences displayed by the participants, and coding each instance with one of the groups from the affinity diagramming. Each audio-recording was coded by one of the authors. Finally, in the fifth step we excluded the 'other' group ( 5 annotations) and arranged the remaining 21 groups into types. While the groups retained some project-specific distinctions, the types were fairly generic.

At the end of the five-step process 631 annotations had been arranged into 21 groups and the groups into seven types. Appendix A lists the competences along with the identified skills and knowledge areas that constituted each competence. The knowledge areas correspond to the simplest level of Bloom's 
taxonomy, the skills to its five other levels. To avoid giving double weight to the six meetings coded by both authors, the annotations from these meetings will be counted as contributing half an instance of a competence. With this modification the participants displayed a total of 433 instances of competences in the course of the 17 meetings.

\section{Results}

Table 1 shows the seven types of competences involved in configuring the electronic whiteboard and preoperative work practices for each other. Managing the project and understanding practice were the two largest competence types, conversely understanding technology was the second smallest. Preparing, making, and assessing change were similarly large competence types. The smallest competence type was personal traits. In the following we describe each type in turn.

Table 1. The seven competence types and the 21 subordinate competences

\begin{tabular}{|c|c|c|}
\hline Type of competence & Count & Percent \\
\hline $\begin{array}{l}\text { Managing the project } \\
\text { Meeting facilitation (40\%), project management (35\%), rationale } \\
\text { for the effects-driven approach (15\%), project scope }(11 \%)\end{array}$ & 86 & 20 \\
\hline $\begin{array}{l}\text { Understanding practice } \\
\text { Current practice (49\%), grounded evaluation (30\%), acceptance } \\
\text { and barriers ( } 21 \%)\end{array}$ & 94 & 22 \\
\hline $\begin{array}{l}\text { Understanding technology } \\
\text { Understanding technology (100\%) }\end{array}$ & 36 & 8 \\
\hline $\begin{array}{l}\text { Preparing change } \\
\text { Detailing work procedures (38\%), modeling interventions (24\%), } \\
\text { envisioning the future ( } 21 \%) \text {, effects specification (17\%) }\end{array}$ & 55 & 13 \\
\hline $\begin{array}{l}\text { Making change } \\
\text { Informing about interventions (61\%), implementing change } \\
(29 \%) \text {, motivation }(10 \%)\end{array}$ & 74 & 17 \\
\hline $\begin{array}{l}\text { Assessing change } \\
\text { Quality assessment of data ( } 43 \%) \text {, specification of measurements } \\
(22 \%) \text {, reflecting on the basis of data (19\%), strategic reflections } \\
\text { (9\%), reflecting on the basis of evidence guidelines }(6 \%)\end{array}$ & 70 & 16 \\
\hline $\begin{array}{l}\text { Personal traits } \\
\text { Personal traits }(100 \%)\end{array}$ & 18 & 4 \\
\hline Total & 433 & 100 \\
\hline
\end{tabular}

\subsection{Managing the project}

Managing the project contained four of the 21 groups: meeting facilitation (40\%), project management (35\%), rationale for the effects-driven approach (15\%), and project scope (11\%). This competence type concerned the shaping, maneuvering, and steering of the project at the overall level as well as the level of the individual meeting.

Meeting facilitation was about the basics of conducting the individual meeting. This competence involved walking through the meeting agenda to align participants, recounting what had happened at previous meetings, keeping the discussion on track, shifting the focus to the next item on the agenda, and summarizing the discussions and decisions made. A specific move in performing this competence was to relate the content of the current discussion to the overall purpose of the project, thereby reminding the participants about the big picture: 
The way we have discussed the fasting time has been that it, of course, is a concept that is easy to relate to. But the purpose of focusing on the fasting time was not just the fasting time itself. It was also that a focus on the fasting time was a means of working with the entire issue of coordinating the planning of the surgical operations. [Meeting \#11, researcher]

Project management involved negotiating and fulfilling the conditions for conducting the project. This competence was about issues that went beyond any individual meeting. It included issues such as ensuring that the three local healthcare professionals were compensated for their participation in the project, aligning project activities with other initiatives to increase momentum, keeping the project separate from other initiatives to avoid confusion, negotiating an extension of the project, and continuously working to sustain management support for the project. An important aspect of this competence was the ability to recognize the situations where the project group lacked knowledge about the conditions within which the project was operating, and a readiness to act on such knowledge gaps:

If the department managers will not commit to working with the fasting times then I go directly to [hospital management] to ask what the departments have agreed to. [Meeting \#5, researcher]

The rationale for the effects-driven approach was the competence of knowing the method according to which the project was run and being able to infer its implications for the activities to be performed and decisions to be made. Because the fasting-time project followed the effects-driven approach the pursued effect of reducing the preoperative fasting times was specified up front, whereas the means of obtaining this effect were left open. This way, the project had substantial freedom in choosing means that on the basis of local experimentation were considered appropriate and effective. Being prepared to embrace this freedom to experiment was essential to the project:

It may be an unfamiliar way of working. The unfamiliar part is that it is the clinicians who drive it. Such a quality-improvement process is bottom-up so to speak; you proceed by experimenting. There is no fixed procedure, rather we have to work it out ourselves. [Meeting $\# 14$, researcher]

If the project had followed another method then it would have been the rationale of that method the participants needed to understand. The need to understand and work by the chosen method would, however, have been the same.

Project scope concerned the competence to reason about the project boundaries. The project participants displayed this competence when they argued the need for including different clinical departments in the project and when they countered the early decision by hospital management to leave the emergency department out of the project. Many of the surgical patients came from the emergency department, thus leaving it out of the project excluded many relevant considerations about how to shorten the fasting times. The project scope was also discussed at the level of the staff groups involved in the project. These discussions mostly concerned the implications of the physicians' limited involvement after the fasting-time effect had been specified:

Then we are, to put it bluntly, the wrong forum. The physicians should make this decision because they are the ones who schedule the operations and need to change this schedule on the basis of information about the fasting times. [Meeting \#5, manager]

\subsection{Understanding practice}

Understanding practice consisted of the groups current practice (49\%), acceptance and barriers (21\%), and grounded evaluation (30\%). This competence type was about coming to grips with the particulars of local practices and relating them to the fasting-time project. Specifically, current practice provided the knowledge base for future action, acceptance and barriers concerned current affairs, and grounded evaluation looked back at past events. 
Current practice involved knowing the practices, procedures, and norms at the hospital. Such knowledge was an indispensable background for working to reduce the fasting times. The project participants for example knew how the preoperative coordination was currently accomplished, how peripheral the patients' fasting time was to this coordination, how new procedures were instituted at the hospital, how the current use of the whiteboard differed across departments, who in practice kept the whiteboard current, and so forth. Key to this competence was an appreciation of the interconnectedness of the practices; it was futile to attempt to change one element in isolation from the others. For example, when an operation was postponed until the next day it was clinically straightforward to allow the patient to have something to eat but actually providing a meal was not always possible:

That is not possible until $5 \mathrm{pm}$. In this place, you cannot have a light evening meal outside the dining hours. There is no food to serve. [Meeting \#16, nurse]

Operations frequently had to be rescheduled for clinical reasons, such as to make room for more urgent, ad hoc operations. Unless such clinical decisions happened to be aligned with the dining hours the patients had to make do with a sandwich or to continue fasting.

Acceptance and barriers concerned the identification, discussion, assessment, and utilization or avoidance of factors that influenced the efforts to reduce the fasting times. This competence was much more directed in its focus on factors that might facilitate or impede the efforts than the previous competence. It was for example identified as a major barrier that efforts to reduce the fasting time increased the risk of occasionally not having any surgical patient who had fasted for the required six hours. Even if this risk was small it meant an idle operation slot, and idle slots were a serious matter:

He [the head of a surgical department] understands it when I explain to him why we record the fasting time and why we focus on it, but his primary focus is to ensure that all operation slots are used. Because his key performance indicator depends on full utilization of the slots. [Meeting \#9, secretary]

To avoid idle slots the department head was more inclined always to have, at least, two patients ready for operation: If it turned out that the first of them for some reason could not be operated anyway then the second could be operated instead. However, in most cases the first patient could be operated and the second, consequently, experienced prolonged fasting. Competence in identifying such barriers was a prerequisite for working to circumvent them.

Grounded evaluation was the competence of reflecting on why specific events, or the project at large, had developed the way they had. Like the two previous competences, this competence was about understanding practice and relating this understanding to the fasting-time project. Unlike the two previous competences, grounded evaluation looked back on the project. Because the fasting-time project was discontinued before a reduction of the fasting time was accomplished, the project participants' evaluations mainly revolved around the challenges of obtaining this effect. The participants for example analyzed the reasons why the physicians had been reluctant to engage in reducing the fasting times, reflected on their difficulties in accomplishing change in their own departments, and discussed the importance of getting the departments to take ownership of the changes required to reduce the fasting times. Grounded evaluations were important for the participants to come to an understanding of the circumstances that strongly influenced the project outcome; such an understanding would inform their future actions.

\subsection{Understanding technology}

This competence type contained only one of the 21 groups and was about understanding the technological options provided by the whiteboard in relation to the fasting-time project. The instances of this competence included knowledge about how the whiteboard was configured at other hospitals in the healthcare region as well as knowhow about how to configure the whiteboard. While the former provided ideas for visualizing the fasting times on the whiteboard, the latter provided the ability to 
turn ideas into technical solutions. The solutions, in terms of whiteboard configurations, were made in-between the meetings but described at the meetings, sometimes in technical detail:

You open the column [on the whiteboard] and then you make a header text, such as "fasting", and [continues to explain the other property settings involved in creating a new whiteboard column]. [Meeting \#3, nurse]

Having the competence to configure the whiteboard also meant that it was possible to assess whether candidate solutions were easy to make or beyond the options afforded by the facility for configuring the whiteboard. It facilitated the discussions at the meetings that such assessments could be made on the spot:

I think that it [i.e., the introduction of fasting-time columns on the whiteboard] can be done. In fact, I think it will be very easy to do. The bigger challenge will be to get the clinicians to use them. [Meeting \#2, nurse]

Assessments like this one could be made on the spot because the local participants in the project had the necessary competence. They had this competence partly because they were super users of the whiteboard and partly because its configuration facility was fairly easy to use.

\subsection{Preparing change}

Preparing change consisted of the groups envisioning the future (21\%), effects specification (17\%), modeling interventions (24\%), and detailing work procedures (38\%). This competence type was about defining the pursued change and the means deemed necessary to make it happen.

Envisioning the future was about generating ideas for future ways of working and critically reflecting on these possible future practices. This competence required creativity, imagination, and designoriented thinking. In the fasting-time project the envisioning consisted partly of considerations about how the work should be organized and partly of considerations about who should do it. The considerations about who should do the work were integral to the participants' reflections on whether an envisioned future practice was realistic:

I am also thinking: who should do it? As it is, the physicians already have difficulty prioritizing the acute operations, so if they also have to specify when each operation will start then... I am just thinking that in the place where they currently write their prioritization - ' 1 ', ' 2 ', ' 3 ' and so forth - in that place they could simply write the estimated time. There is no need to write the time somewhere else when we already have the prioritization. The physician could simply write 'approx. 8am', 'approx. 10am' and so forth. Then, the nurse could update this estimate if the patients are subsequently reprioritized. [Meeting \#5, manager]

While this change may appear mundane, it would make it explicit that the patients prioritized as number four and higher were unlikely to be operated within the next six hours and, thereby, possibly trigger considerations about giving them something to eat.

Effects specification involved stating the pursued effect in detail. That is, it involved agreeing on what the project specifically sought to achieve. While the focus on reducing the fasting time had been set ahead of the project meetings, the fasting-time effect still had to be defined in detail. At the concrete level, the events that indicated the beginning and end of the fasting period had to be decided. For example, it had to be decided whether fasting started when the patient last ate or at the point in time from which the patient was instructed to abstain from eating. At the overall level, this decision influenced the scope of the project by shaping which factors entered into determining the duration of the fasting period. In this way, the effects-specification competence was related to the competence about the project scope. Both competences were about setting the boundaries of the project and, thereby, about balancing a scope that was sufficiently large to accomplish changes that mattered against a scope that was sufficiently small to be manageable by the project group. 
Modeling interventions consisted of formulating work-practice changes that would help reduce the fasting times. This competence was needed because the extension of the whiteboard with fasting-time information was, in itself, not sufficient to change the fasting times. In addition to a way of recording the fasting-time information on the whiteboard, it was necessary to devise ways of integrating the use of the recorded information in clinical practices. There was little need for experimentation to arrive at the intervention for recording the fasting-time information; this intervention quickly proceeded to detailed specification. Much more analysis and experimentation was needed to think of functioning interventions for integrating the use of the recorded information in clinical practices, probably because it was the use of the fasting-time information, not its recording, that had consequences for the coordination of the operations. Multiple candidate interventions were formulated and discussed at the meetings. The project participants preferred interventions that integrated the use of the fastingtime information in collaborative practices (specifically a daily timeout) rather than in individual practices. It was felt that collaborative practices were more likely to lead to deliberations in which the fasting time became a factor.

Detailing work procedures consisted of describing in detail the procedures that realized the modeled interventions. For the daily timeout this competence, for example, involved the ability to devise when it should take place to fit into the coordination of the operations, who should participate to ensure that decisions about the patients' fasting could be made at the timeouts, and where to conduct the timeouts to have the whiteboard available. In this way, detailing the work procedures involved shouldering the managerial responsibility of planning aspects of other clinicians' work. Detailing the work procedures also involved thinking through the exceptions from the normal flow of events. One important source of exceptions was cancelled operations, which often caused rework:

We cancel an insane number of operations. When you have entered all the data [about the operation of a patient] into the system then you'd like to keep them but that is not always possible, or it creates confusion. Sometimes it is simply better to bite the bullet, delete the data, and start over again when the operation is rescheduled. [Meeting \#2, secretary]

Cancellations were important in relation to the work procedures for fasting times because they necessitated a special workflow to ensure the correct recording of the end of the fasting period. To be acceptable to the local participants' colleagues a procedure had to ensure correct recording while at the same time minimizing rework.

\subsection{Making change}

Making change consisted of motivation (10\%), informing about interventions (61\%), and implementing change (29\%). This competence type concerned the participants' ability to set the planned change in motion by having their colleagues adjust their ways of working. Compared to the previous competence types, making change shifted the focus from preparatory work in the project group to the execution of work external to the project group.

Motivation was about linking long fasting times to established problems and shorter fasting times to improvements in the handling of these problems. Thereby, the project participants sought to instill a focus on fasting times among their colleagues. The participants for example revisited the argument that there was clinical evidence for adverse health effects of long fasting times, at least for some patient groups. This argument was pertinent to convincing the physicians to incorporate the fastingtime information in their practices. The clinical evidence for the adverse effects of long fasting times included indications that the patients stayed longer in hospital. This piece of evidence communicated well to management. A representative of hospital management commented:

If you reduce the patients' length of stay by an hour or so then, all of a sudden, you have freed four beds... We have to remember that a couple of hours for each of the many surgical patients add up to a lot. And that capacity is currently used without creating value for the citizens. [Meeting \#12, manager] 
In motivating shorter fasting times the participants also linked fasting times to patient satisfaction. This was done most forcefully by a participant who equated fasting time with waiting time: "I would hate to wait 14 hours if I was acutely ill and needed an operation." This argument spoke more directly to values like compassion.

Informing about interventions involved communicating the new procedures to the clinicians. This competence was partly about choosing appropriate communication channels and partly about skills in presenting the procedures for recording and using the fasting-time information in a convincing and straightforward manner. With respect to channels, the project participants relied mainly on oral communication to invite questions and be able to resolve them immediately and collaboratively:

In my experience it makes a difference when you physically go out there, in the departments, and ask: Do you experience any problems with this? Is there anything you need help to do? That is, you take it directly face to face instead of writing information mails and such. It is about being there and saying: Let's solve this together. [Meeting \#5, nurse]

The project participants also made themselves available for consultation by dropping by the whiteboard in the different departments and otherwise attending situations where the fasting-time information might be relevant to the clinicians. Because they, for obvious reasons, could only attend few of these situations they also worked to ensure that the chief physicians in the departments promoted the importance of starting to use the fasting-time information for reducing the patients' fasting times.

Implementing change consisted of reminding the clinicians about the new procedures, ironing out obstacles to adopting the new ways of working, and formally inscribing the new ways of working in standard procedures. This competence was the direct continuation of the previous competence of informing about the interventions because the project participants largely construed the previous competence in the in-situ manner of approaching the clinicians when they concretely were to comply with the procedures. If the previous competence had been construed more as a matter of organizing information meetings then the contrast between the two competences would have been sharper. As it were, the project participants spent time monitoring their colleagues and politely reminding them about the fasting time when they forgot to record it or appeared to disregard it in decisions about the coordination of the operations:

It takes a while before it is something they do near automatically. So we probably have to monitor whether it happens and remind them when it doesn't. [Meeting \#17, secretary]

The procedure for recording the fasting-time information on the whiteboard was formalized by making it a standard procedure at the hospital. This formalization stipulated who was responsible for recording the information for different types of patients and, thereby, provided an authoritative argument in any discussions about how the change should be implemented.

\subsection{Assessing change}

Assessing change consisted of specification of measurements (22\%), quality assessment of data (43\%), reflecting on the basis of data (19\%), reflecting on the basis of evidence guidelines (6\%), and strategic reflections (9\%). This competence type was about appraising the situation after the implementation efforts, comparing it with the pursued change, and reflecting on what had and had not been accomplished.

Specification of measurements consisted of defining how to measure whether the fasting-time effect was achieved. That is, it involved determining the data that had to be recorded to make it possible to calculate the fasting times and examine them for relevant patient subgroups. This competence was tightly related to the competence of effects specification. An aspect specific to the specification of the measurements was ensuring that the fasting-time information could be extracted from the whiteboard for the calculation of the average fasting time. On the whiteboard the fasting times merely appeared for each patient individually. Extraction of data from the whiteboard was not a routine matter at the 
hospital; thus, it was important to ensure that it could be done at the intervals needed to follow how the fasting time evolved after the fasting-time effect became a focal issue.

Quality assessment of data was the competence of scrutinizing data from the effects measurements to spot potential errors and initiate the required cleaning of the data. This competence required local knowledge about the approximate number of patients of different types and the factors that influenced the duration of their fasting period. Such knowledge was a prerequisite for assessing whether the data appeared reasonable and, if not, for narrowing down what the error might be. Data of poor quality would produce misleading results as well as destroy the credibility of the project with the clinicians. Thus, quality assessment was an important competence.

Reflecting on the basis of data was about using the extracted and quality-assessed data for making inferences about the extent to which the pursued change had been accomplished. One aspect of this competence involved pondering whether the average fasting times were problematically long or just longer than the required six hours. For the acute, as opposed to elective, operations a chief physician from the emergency department expressed surprise about the long duration of the fasting period:

As a non-surgeon it puzzles me that the acute patients are fasting longer than the elective patients. I would have assumed that they were operated here and now, whereas the elective, whom we essentially do not consider ill, could wait. So it takes me aback that they [i.e., the acute patients] wait so long. [Meeting \#12, physician]

This comment implied that the fasting times were problematically long, at least for the acute operations. It also showed that the physician's intuition about the fasting times was inaccurate, thereby demonstrating the value of reflecting on the basis of data. Another aspect of this competence consisted of using the data to assess the effectiveness of the interventions intended to make the clinicians record and use the fasting-time information. If the interventions were not effective then the participants needed to revise them or devise new interventions. Such assessments and revisions depended on local knowledge for understanding why interventions succeeded or failed and how they could be improved. In essence, the competence of reflecting on the basis of data was about utilizing measurement data to activate local knowledge.

Reflecting on the basis of evidence guidelines complemented the previous competence and consisted of using clinical evidence from the research literature in pondering local issues. This competence was not a disregard for the data from the measurements but an ability and readiness to relate to these local data through the results and recommendations accumulated in the medical literature. In the project, evidence guidelines were merely used in reflecting on whether the average fasting times were problematically long; they could, in principle, also have been used for recommending some interventions as more likely to be effective than others. The inclination to evidence-based thinking was strongest among the managers and physicians (see Section 5.8).

Strategic reflections involved relating shorter fasting times to issues of strategic importance to the hospital. This competence was the post hoc equivalent of the motivation competence, which facilitated the project participants in making change. The participants for example considered the strategic value of shorter fasting times in marketing the hospital toward elective patients outside its immediate catchment area. Because shorter fasting times implied improved coordination of the operations it would, in turn, make the hospital better able to schedule in advance precisely when elective patients would be operated. This would be a valuable improvement over the current state of affairs in which all elective patients were requested to arrive at 7am:

We have a fair number of patients who come from [the neighboring healthcare region]. It can easily take them a couple of hours to drive down here in the morning, and some of them complain that 'I got up at 4 am to be here now [at 7am] only to be informed that I am number three on the program and will not be operated until $1 \mathrm{pm}$ '. [Meeting \#12, secretary] 


\subsection{Personal traits}

This competence type contained the last of the 21 groups and was about the personal impact that followed from being able to talk knowledgeably and convincingly about the issues that influenced the patients' fasting times. While ample knowledge of local practices and problems was a prerequisite for this competence, it also required charisma in presenting how the fasting-time project might alleviate the problems and improve practices. Having this competence provided participants with an informal position that, at least to some extent, substituted for their limited formal decision power:

I have no decision power in my position but I actually find that people tend to listen to me and mostly go along with the things I propose. [Meeting \#14, nurse]

This participant in the project group had long been informally recognized by her colleagues as an authority on the use of the whiteboard. The informal recognition had motivated her appointment as super user and it also extended into her work in the fasting-time project, thereby lending weight to the project.

\subsection{Spread of competences across participants and time}

To get an indication of how the competences were spread across the participants we grouped the participants who displayed the competences into local participants (the three healthcare professionals in the project group), researchers (the authors and the research assistant), and other (representatives of management and physicians). Table 2 shows that the local participants displayed $57 \%$ of the 433 competence instances, the researchers $32 \%$, and the managers and physicians merely $11 \%$ (because they were only represented at 3 of the 17 meetings). The researchers dominated the competence type of project management, in particular meeting facilitation (99\%) and the rationale for the effects-driven approach (68\%). In contrast, the local participants dominated the six other competence types: understanding practice, understanding technology, preparing change, making change, assessing change, and personal traits. The managers and physicians dominated only the competence that most explicitly reflected a physician mindset, namely the assessing-change type competence of reflecting on the basis of evidence guidelines (89\%).

Table 2. The percentage of the seven competence types displayed by each participant group and during each half of the project

\begin{tabular}{lrrrrrrr}
\hline Type of competence & \multicolumn{3}{c}{ Participant group } & & \multicolumn{2}{c}{ Project half } \\
\cline { 2 - 3 } \cline { 6 - 7 } & Local & Researcher & Other ${ }^{\text {a }}$ & & First half & Second half \\
\hline Managing the project & 25 & 67 & 8 & & 54 & 46 \\
Understanding practice & 67 & 20 & 13 & & 43 & 57 \\
Understanding technology & 64 & 25 & 11 & & 78 & 22 \\
Preparing change & 61 & 27 & 12 & & 52 & 48 \\
Making change & 66 & 25 & 9 & & 53 & 47 \\
Assessing change & 60 & 22 & 18 & & 25 & 75 \\
Personal traits & 78 & 22 & 0 & & 42 & 58 \\
\hline Total & 57 & 32 & 11 & & 48 & 52 \\
\hline
\end{tabular}

${ }^{a}$ The managers and physicians who constituted the 'other' group were only present during 3 of the 17 meetings

To get an indication of how the competence types were spread across time we compared the meetings during the first half of the project with those during the second half of the project, see Table 2 . Five of the competence types were evenly spread between the first and second half of the project, thereby 
suggesting a continuous need for the participants to manage the project, understand practice, prepare change, make change, and for their personal traits. Only two competence types were unevenly spread. The need for understanding technology was mostly present early on; as much as $78 \%$ of the instances of this competence type were displayed during the first half of the project. In contrast, only $25 \%$ of the instances of assessing change were displayed during the first half of the project; this competence type was mostly needed later on.

\section{Discussion}

In his study of the risks to successful systems development Boehm (1991) identifies personnel shortfalls as the top risk. In a similar vein Curtis et al. (1988, p. 1284) note that "we were constantly confronted with the impact of individual talent and experience on a project". Thus, the importance of competences held by, or absent among, project participants is well-established. The importance of having the best possible competences for configuring systems and practices accentuates the organizational responsibility for nurturing these competences but also the opportunity for individuals to make a career by exercising and honing them.

\subsection{Competences needed locally}

Healthcare clinicians are educated in medicine, nursing, and similar fields, hired on the basis of their skills in these fields, and tasked with treating and caring for patients. When they engage in the configuration of systems and work practices it is most likely a secondary task for which they have a more informal and uneven background. The same applies in areas other than healthcare. Consequently, it cannot be taken for granted that the competences needed locally will also be present locally. In summary, we find that seven types of competences are needed locally to configure systems and practices for each other:

- Managing the project, that is the shaping, maneuvering, and steering of the individual project activities and of the project at large. In the fasting-time project the researchers dominated this, and only this, competence type but we expect that it will in most cases be present locally. Project management is not a competence specific to the configuration of systems and practices after golive but, for example, also required from information-systems professionals (Topi et al., 2017).

- Understanding practice, that is the analysis and grappling with the particulars of local practices to connect them to a project. While this competence type is scarce among external designers (Curtis et al., 1988), it is common among local actors because it is part and parcel of their primary work. Local actors may, however, be unfamiliar with applying their understanding of practice in a change context. Translators (Mackay, 1990) are valuable exactly because they master such application.

- Understanding technology, that is knowledge about how others have configured the technology and knowhow about how to configure it. In the fasting-time project understanding technology was the second smallest competence type, thereby suggesting that it was a smallish issue. In contrast, other studies often find that local actors need external support regarding this competence type (e.g., Dittrich et al., 2002; Hartswood et al., 2002).

- Preparing change, that is the envisioning, modeling, and detailing of the pursued change and of the means necessary to make it happen. Innovators (Rogers, 2003) excel in the creativity and experimentation involved in this competence type. It may, however, be foreign to local actors if they are more used to comply with procedures than rewrite them. Such work conditions will likely also mean that the next competence type is not present locally, at least not fully.

- Making change, that is the implementation of the change by informing local actors and motivating them to adjust their practices. More so than the other competence types, this competence type benefits from a formal organizational position (Ginsberg \& Abrahamson, 1991). The peripheral participation of physicians in the fasting-time project illustrates the problem. Competence in making change is sufficiently rare to be highly valued (Rasmussen et al., 2011). 
- Assessing change, that is the appraisal of the new situation and reflections on what has, and has not, been accomplished. This competence type corresponds to the highest level in Bloom's taxonomy (Bloom et al., 1956). The fasting-time project showed the value of reflecting on the basis of data because they disclosed inaccurate intuitions. While external support may be needed to collect such data, their assessment is essentially a matter of activating local knowledge.

- Personal traits, that is the personal impact that follows from being able to talk knowledgeably and convincingly about how the change will improve local matters. This competence type overlaps with the individual foundational competences in Topi et al. (2017). In addition, the personal traits resemble the attributes of opinion leaders and change agents (Rogers, 2003), thereby indicating that this competence type can be present locally, externally furnished, or both.

Even if several of the competences may appear straightforward from the point of view of someone trained in a field like information systems, it is important to keep in mind that for someone without such training they are an 'extra curriculum'. We contend that preparing and making change are, probably, the two competence types that are most thinly spread locally because change is genuinely difficult to accomplish and because many local actors infrequently exercise these competences in their primary work.

\subsection{Challenges in accomplishing change locally}

The main challenge in configuring systems and practices for each other is that all seven competence types must be present. For example, Markus (2004) notes that technological change is restricted to near trivial improvements in organizational performance if it is made without accompanying organizational change. To make appreciable improvements it is necessary to understand technology as well as practices and to be able to change them in concert. Even if change in, say, tasks is not planned it will likely happen when technology or another organizational component is changed. Thus, competence in preparing, making, and assessing change in one or the other of systems and practices cannot be planned away: "Clearly most efforts to effect change, whether they take off from people, technology, structure or task, soon must deal with the others" (Leavitt, 1964, p. 56). Inability to do so will result in unfocused efforts or trivial improvements. Inability to manage projects or lack of personal traits may also prevent the successful configuration of systems and practices, even if the other competence types are locally present.

The seven competence types become necessary because design-in-use efforts such as the fasting-time project strive to change collaborative work arrangements. A collaborative work arrangements is challenging to change because the group of collaborating actors must act in concert to accomplish the change. The competence type of making change is entirely about creating concerted action but the other competence types are also shaped by being means toward reconfiguring a collaborative work arrangement. For example, the personal traits involve the ability to impact others in discussions about how the change will improve local matters. Fewer competences would be required to configure systems and practices for each other if the aim was merely to customize the systems for individual actors' personal use. Mackay (1990) investigated this simpler case and found that customizations for improving individual work were often made by a few people and then shared among colleagues. More boundaries are crossed - and must therefore be competently negotiated - when collaborative work arrangements are reconfigured than when systems are customized for individual use. For example, the fasting-time project crossed boundaries between departments, between professional groups, and between patient types. Changes that cut across such established boundaries are more difficult to accomplish than changes within the boundaries (Sanchez \& Mahoney, 1996).

Another challenge in the configuration of systems and practices is the need for iterative experimentation to arrive at a configuration that works well (Simonsen \& Hertzum, 2008). Many users expect that the systems and practices introduced in their organization have been configured for each other prior to go-live (Torkilsheyggi \& Hertzum, 2017). These users are not prepared to engage in experimentation, which they will experience as a disturbance in their primary work. The competence 
of making change involves motivating these colleagues to change their ways of working one or several times in the pursuit of effects such as reduced fasting times. Several attempts may be needed to achieve a pursued effect because the first interventions may only be partly adopted in the organization, because they may prove ineffective, because they may yield results that transform the effect, or because unanticipated side effects emerge and call for further interventions (Hertzum \& Simonsen, 2011). The local configuration of systems and practices is needed for the very reason that experimentation based on real-use experience with systems is needed to work toward achieving benefit from them. Without experimentation the system configuration and work practices will likely congeal prematurely (Tyre \& Orlikowski, 1994). Presumably, more complex change processes require more experimentation but also create more uncertainty in the organization and thereby reduce its tolerance for experimentation. Thus, the pressure on local competences to prepare and make change increases progressively with situations that encompass a large need for experimentation.

Bygstad (2017) distinguishes between lightweight and heavyweight technology and argues that lightweight technology provides better support for configuration and change. The electronic whiteboard in the fasting-time project is an example of a lightweight technology. Its technological complexity is modest because it, for the most part, consists of a front-end that presents information from other hospital systems in new ways. In contrast, heavyweight technology bears the cost and complexity of back-end development and consists of integrated infrastructures that remain in operation for decades. While heavyweight technology is the realm of software engineers, the modest technical sophistication of lightweight technology invites configuration and experimentation by local actors. That is, lightweight technology meets the call by Lieberman et al. (2006) for systems that are easy to modify, not just easy to use. The fasting-time project demonstrates that the relative ease of configuring the whiteboard shifts the bulk of the necessary competences from technology toward changes in work practice. However, it also demonstrates that lightweight technology does not preclude a heavyweight organization, in which change requires wrestling with interlocking procedures, job specialization, longstanding arrangements, and safety-critical tasks. These organizational characteristics increase the demands on local competences for accomplishing change. And in contrast to much design-in-use research (e.g., Dittrich et al., 2002; Hartswood et al., 2002) they suggest that local actors may be more in need of support for configuring work practices than information technology.

Finally, change is assessed in multiple and competing ways. The local actors must be able to appreciate and accommodate such assessments in their configuration of systems and practices (Okamura et al., 1995; Aanestad et al., 2017). Reflecting on the basis of data, evidence guidelines, and strategic considerations are different avenues to assess the change and must be merged into a negotiated agreement about what has been accomplished and how to proceed. Failure to accommodate the different assessments of the change constitutes a risk to project progress, especially if the discounted assessments are held by powerful actors. In the fasting-time project it became a barrier that the physicians took part in identifying the fasting-time effect but assumed a peripheral role in the project established to achieve it. The physicians' limited participation increased the risk that their viewpoints were inadvertently discounted and it, in turn, decreased the weight they attached to the project. This speaks to the value of involving such powerful stakeholder groups in local projects. Alternatively, it must be ensured that the local project group includes the personal traits necessary to talk knowledgeably and convincingly with all stakeholder groups of importance to accomplish the change. We also note that the impact of external evidence and guidelines on the assessment of local change efforts may be more prominent in healthcare than in most other domains, which often lack similarly authoritative external sources of evidence.

\subsection{Implications}

We want to emphasize three implications of this study. First, local configuration activities extend the useful lifetime of systems because they can target needs and opportunities that emerge as circumstances evolve. That is, the local configuration activities will be spread over time. While 
configuration activities immediately after go-live will often be preplanned and performed with the support of external consultants, the subsequent configuration activities are more improvisational and more likely to depend exclusively on local competences. The local presence of competences in configuring systems and practices for each other, thus, appears key to the long-term realization of benefits from investments in information systems.

Second, by making competences the focal issue we shift the attention from processes and tools to the people who perform design in use. While it is well-known that people are critical to the successful introduction of information systems, the actual array of competences that are needed locally must be known to organizations in order for them to staff projects appropriately or initiate the necessary competence building. Decisions to supplement local staff with organization-internal support or organization-external consultants should also be informed by knowledge of the full array of competences needed and considerations about how to bring these competences to bear in an integrated manner.

Third, students and local practitioners can use the catalog of the 21 competences to get an overview of the competences needed to fulfil the local role of configuring systems and work practices for each other after go-live. This overview may assist them in deciding whether it is an attractive career path and may, if so, guide them in their selection of courses and other training activities. Appendix A supports this use of the study by providing a competence profile for the role of configuring systems and practices. For each competence the appendix gives the associated skills and knowledge areas (extracted from our empirical data).

\subsection{Limitations}

Three limitations should be remembered in interpreting the results of this study. First, we acknowledge that the competences cataloged in this study are derived from one project and should be tested in studies involving technologies other than whiteboards, domains other than healthcare, methods other than the effects-driven approach, and cultural contexts other than Denmark. The competences identified in the present study provide a reference point for future research on establishing a consolidated catalog of competences. Second, the project group included representatives of nurses and secretaries but no representatives of the physicians. We tried to recruit physicians as well, but without success. In the end we settled for physician participation in three of the project meetings. A different composition of the project group might change the prominence of some competence types; for example, the need for understanding technology might increase. In addition, change was more cumbersome to accomplish without physicians because they were instrumental to the coordination of surgical operations and, thereby, to fasting times. Third, the project ended without obtaining shorter fasting times. The principle reason for closing the project was an external event, namely the decision to replace the whiteboard with a new region-wide electronic patient record. We cannot know whether shorter fasting times would have been obtained if this external event had not occurred. That is, we cannot conclude that the 21 competences are a complete catalog of the competences needed locally to obtain a specified effect.

\section{Conclusion}

On the basis of a project at a Danish hospital we have catalogued 21 competences needed locally to configure information systems and work practices for each other. These competences are important because system design is increasingly completed by local actors who engage in configuration activities after systems have gone live. The competences can be arranged into seven types, all of which are needed to tailor a system to local circumstances and reap benefit from it. The seven types are: managing projects, understanding practice, understanding technology, preparing change, making change, assessing change, and personal traits. Competences that are not present locally must be build, externally furnished, or sorely missed. Apart from the period immediately following go-live they will seldom be externally furnished. 


\section{Acknowledgements}

This study is part of the Clinical Communication project, which is a research and development collaboration between Region Zealand, Imatis, Roskilde University, and University of Copenhagen. The study was financially supported by Region Zealand. Research assistant Lene Hansen provided practical support and transcribed the ten selected meetings. We owe thanks to all the clinicians who took part in the activities of the fasting-time project. Special thanks are due to the three hospital representatives in the project group: Dorte S. Jensen, Helle P. Dengsøe, and Monica H. Marqvorsen.

Declarations of interest: The authors took part in the fasting-time project and, thereby, also in the project meetings analyzed in this paper. Apart from this participation we have no conflicts of interest to declare.

\section{Appendix A: competence profile}

For each of the 21 competences, the competence profile lists the associated skills and knowledge areas. Thereby, the competence profile complies with the typology of knowledge, skills, and competences (Winterton et al., 2006). The skills and knowledge areas are extracted from the 433 competence instances in the fasting-time project.

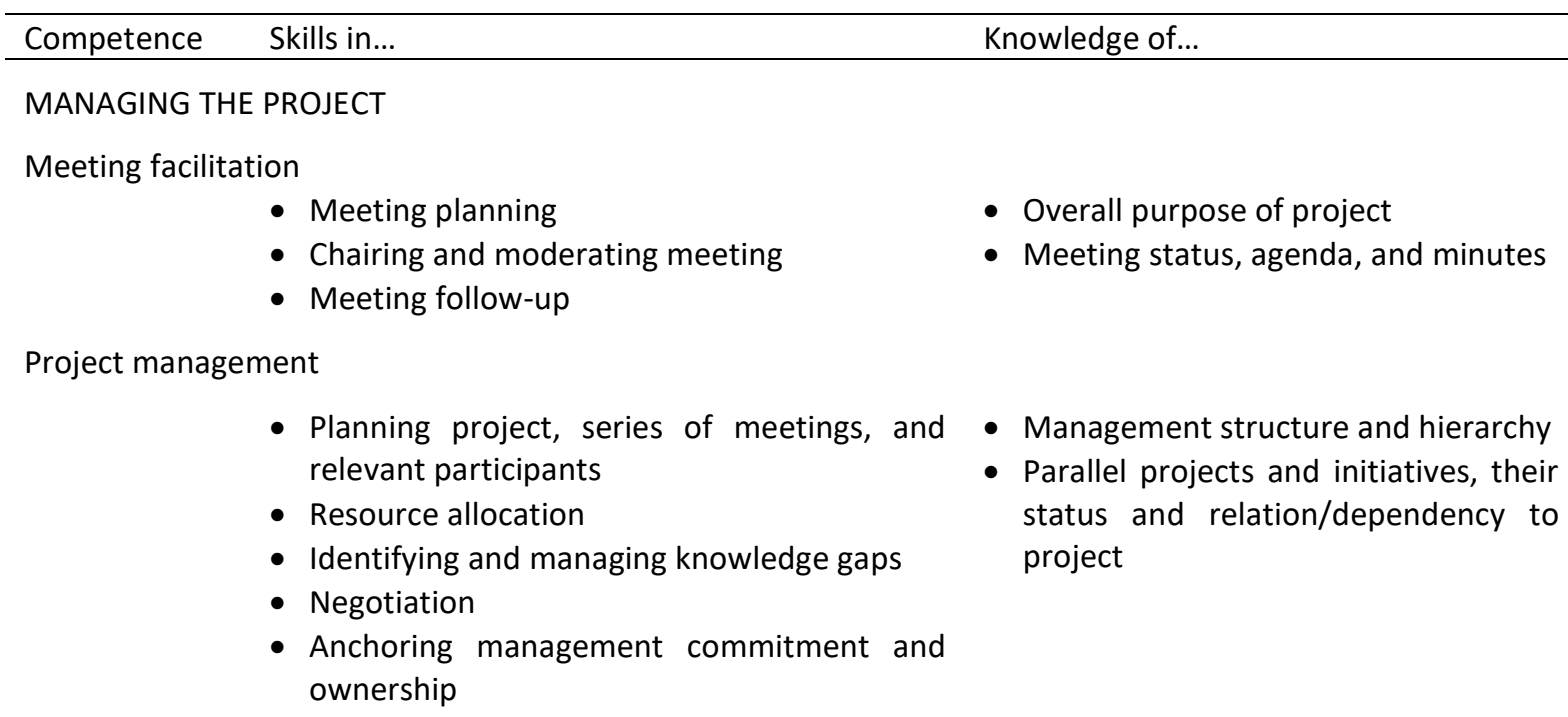

Rationale for the effects-driven approach [or alternative method]

- Understanding the method's basic idea, premise, conditions, rationale, and experimental nature

- Planning project process according to method

- Effects-driven implementation [or alternative method]

- Project change agenda and aim

- Communicating the method and its rationale

Project scope

- Analyzing project boundaries

- Clarifying who to involve and not to involve

- Associated and critical organizational units and stakeholders

- Involving critical stakeholders, competences, and participants

UNDERSTANDING PRACTICE

Current practice

- Critically reflecting on current practice

- Work practices, procedures, norms 
- Analyzing needs, challenges, and problems

Acceptance and barriers

- Analyzing success and risk factors

- Managing risks

Grounded evaluation

- Post-hoc analyzing and evaluating project events and interventions

- Clarifying who to involve in evaluation
- Rules and procedures for technology use

- Technology use patterns throughout the organization

- Technology skills and proficiency for different user groups
- Current success and risk situations/conditions
- Overall purpose and activities of project

- Critical stakeholders

\section{UNDERSTANDING TECHNOLOGY}

Understanding technology

- Technically configuring technology

- Testing new configurations

- Implementing new configurations (go-live)
- Technology configuration options and how to make use of them

- Standards (e.g., naming and layout conventions) for technology configurations

- Procedures for test and implementation (go-live) of new configurations

- Technology configurations made in other organizations

- Other resource persons with technical configuration skills

\section{PREPARING CHANGE}

Envisioning the future

- Design-oriented (sociotechnical) thinking

- Critically reflecting on envisioned future practice

Effects specification [or alternative method's aims/goals/KPIs]

- Understanding effects [or aims/goals/KPIs]

- Analyzing and specifying effects [or aims/goals/KPIs]
- Technology options (current and planned, plus future perspectives)

- Technology use in other organizations

Modeling interventions

- Devising and reflecting on ideas for - Techniques for modeling visualization interventions

- Integrating new technology use with collaborative work practices

Detailing work procedures

- Reflecting on detailed workflows, procedures, and exceptions

- Developing and articulating standard procedures for technology-mediated new work practices

- Overall purpose of project 
- Division of responsibilities (workflow, procedures)

MAKING CHANGE

Motivation

- Reflecting on motivation factors in relation to - Motivation factors project goals

Informing about interventions

- Communicating procedures needed to - Communication channels and establish interventions experience using them

Implementing change

- Managing change

- Division of responsibilities (authorizing changes)

\section{ASSESSING CHANGE}

Specification of measurements

- Translating effects/KPIs into measurable data

- Defining before and after measurements

- Measurement aim (effects/KPIs)

- Scoping measurements (power analyses)

- Data and how data are recorded

- How to extract data

Quality assessment of data

- Assessing data and potential errors

- Cleaning data

- How data are recorded and potential sources of error

Reflecting on the basis of data

- Interpreting data and statistics

- Relating data to current practice including

- Current practice including new new interventions

- Assessing the effectiveness of interventions

Reflecting on the basis of evidence guidelines

- Evidence-based thinking

Strategic reflections

- Strategic analysis and assessment
- Clinical evidence from research literature
- Organizational strengths, weaknesses, opportunities, and threats

\section{PERSONAL TRAITS}

Personal traits

- Drive and energy also during adversity

- Patience and initiative in the face of complexity

- Establishing informal authority

- Involving and committing management

\section{References}

Aanestad, M., Driveklepp, A.M., Sørli, H., \& Hertzum, M. (2017). Participatory continuing design: "Living with" videoconferencing in rehabilitation. In A.M. Kanstrup, A. Bygholm, P. Bertelsen, \& 
C. Nøhr (Eds.), Participatory Design and Health Information Technology (pp. 45-59). Amsterdam: IOS Press.

American Society of Anesthesiologists. (2011). Practice guidelines for preoperative fasting and the use of pharmacologic agents to reduce the risk of pulmonary aspiration: Application to healthy patients undergoing elective procedures. Anesthesiology, 114(3), 495-511.

Balka, E., \& Wagner, I. (2006). Making things work: Dimensions of configurability as appropriation work. In Proceedings of the CSCW 2006 Conference on Computer Supported Cooperative Work (pp. 229-238). New York: ACM Press.

Beyer, H., \& Holtzblatt, K. (1998). Contextual design: Defining customer-centered systems. San Francisco, CA: Morgan Kaufmann.

Bikson, T.K., \& Eveland, J.D. (1998). Sociotechnical reinvention: Implementation dynamics and collaboration tools. Information, Communication \& Society, 1(3), 270-290.

Bjögvinsson, E., Ehn, P., \& Hillgren, P.-A. (2012). Design things and design thinking: Contemporary participatory design challenges. Design Issues, 28(3), 101-116.

Bloom, B.S., Engelhart, M.D., Furst, E.J., Hill, W.H., \& Krathwohl, D.R. (1956). Taxonomy of educational objectives: The classification of educational goals. Handbook I: Cognitive domain. New York: McKay.

Boehm, B.W. (1991). Software risk management: Principles and practices. IEEE Software, 8(1), 32-41.

Bygstad, B. (2017). Generative innovation: A comparison of lightweight and heavyweight IT. Journal of Information Technology, 32(2), 180-193.

Carroll, J.M., Kellogg, W.A., \& Rosson, M.B. (1991). The task-artifact cycle. In J.M. Carroll (Ed.), Designing Interaction: Psychology at the Human-Computer Interface (pp. 74-102). Cambridge, UK: Cambridge University Press.

Chouhan, V.S., \& Srivastava, S. (2014). Understanding competencies and competency modeling - A literature survey. Journal of Business And Management, 16(1), 14-22.

Curtis, B., Krasner, H., \& Iscoe, N. (1988). A field study of the software design process for large systems. Communications of the ACM, 31(11), 1268-1287.

Dittrich, Y., Eriksén, S., \& Hansson, C. (2002). PD in the wild: Evolving practices of design in use. In T. Binder, J. Gregory, \& I. Wagner (Eds.), PDC2002: Proceedings of the Seventh Conference on Participatory Design (pp. 124-134). Palo Alto, CA: CPSR.

EU. (2015). ECTS users' guide. Luxembourg: Publications Office of the European Union.

Folcher, V. (2003). Appropriating artifacts as instruments: When design-for-use meets design-in-use. Interacting with Computers, 15(5), 647-663.

Gallivan, M.J. (2001). Organizational adoption and assimilation of complex technological innovations: Development and application of a new framework. The Data Base for Advances in Information Systems, 32(3), 51-85.

Ginsberg, A., \& Abrahamson, E. (1991). Champions of change and strategic shifts: The role of internal and external change advocates. Journal of Management Studies, 28(2), 173-190.

Glaser, B.G., \& Strauss, A.L. (1967). The discovery of grounded theory: Strategies for qualitative research. New York: Aldine de Gruyter.

Hartswood, M., Proctor, R., Slack, R., Voss, A., Büscher, M., Rouncefield, M., \& Rouchy, P. (2002). Corealisation: Towards a principled synthesis of ethnomethodology and participatory design. Scandinavian Journal of Information Systems, 14(2), 9-30.

Henderson, A., \& Kyng, M. (1991). There's no place like home: Continuing design in use. In J. Greenbaum \& M. Kyng (Eds.), Design at Work: Cooperative Design of Computer Systems (pp. 219240). Hillsdale, NJ: Erlbaum.

Hertzum, M., \& Simonsen, J. (2011). Effects-driven IT development: Specifying, realizing, and assessing usage effects. Scandinavian Journal of Information Systems, 23(1), 3-28.

Hoffmann, T. (1999). The meanings of competency. Journal of European Industrial Training, 23(6), 275286. 
Kanstrup, A.M., \& Bertelsen, P. (2006). Participatory IT-support. In G. Jacucci, F. Kensing, I. Wagner, \& J. Blomberg (Eds.), PDC2006: Proceedings of the Ninth Participatory Design Conference (pp. 8794). New York: ACM Press.

Kensing, F., \& Munk-Madsen, A. (1993). PD: Structure in the toolbox. Communications of the ACM, $36(6), 78-85$.

Krathwohl, D.R. (2002). A revision of Bloom's taxonomy: An overview. Theory Into Practice, 41(4), 212218.

Kujala, S. (2003). User involvement: A review of the benefits and challenges. Behaviour \& Information Technology, 22(1), 1-16.

Lambert, E., \& Carey, S. (2016). Practice guideline recommendations on perioperative fasting: A systematic review. Journal of Parenteral and Enteral Nutrition, 40(8), 1158-1165.

Leavitt, H.J. (1964). Applied organization change in industry: Structural, technical, and human approaches. In W.W. Cooper, H.J. Leavitt, \& M.W. Shelly (Eds.), New Perspectives in Organization Research (pp. 55-71). New York: Wiley.

Leonard-Barton, D. (1988). Implementation as mutual adaptation of technology and organization. Research Policy, 17(5), 251-267.

Lieberman, H., Paternó, F., Klann, M., \& Wulf, V. (2006). End-user development: An emerging paradigm. In H. Lieberman, F. Paternó, \& V. Wulf (Eds.), End-user development (pp. 1-8). Dordrecht: Springer.

Mackay, W.E. (1990). Patterns of sharing customizable software. In Proceedings of the CSCW'90 Conference on Computer Supported Cooperative Work (pp. 209-221). New York: ACM Press.

Mark, G., \& Poltrock, S. (2004). Groupware adoption in a distributed organization: Transporting and transforming technology through social worlds. Information \& Organization, 14(4), 297-327.

Markus, M.L. (2004). Technochange management: Using IT to drive organizational change. Journal of Information Technology, 19(1), 4-20.

McKeen, J.D., \& Guimaraes, T. (1997). Successful strategies for user participation in systems development. Journal of Management Information Systems, 14(2), 133-150.

Mitchelmore, S., \& Rowley, J. (2010). Entrepreneurial competencies: A literature review and development agenda. International Journal of Entrepreneurial Behavior \& Research, 16(2), 92111.

Nygren, J. (2006). The metabolic effects of fasting and surgery. Best Practice \& Research: Clinical Anaesthesiology, 20(3), 429-438.

Okamura, K., Fujimoto, M., Orlikowski, W.J., \& Yates, J. (1995). Helping CSCW applications suceed: The role of mediators in the context of use. The Information Society, 11(3), 157-172.

Orlikowski, W.J. (1996). Improvising organizational transformation over time: A situated change perspective. Information Systems Research, 7(1), 63-92.

Orlikowski, W.J., \& Hofman, J.D. (1997). An improvisational model for change management: The case of groupware technologies. Sloan Management Review, 38(2), 11-22.

Pimenta, G.P., \& de Aguilar-Nascimento, J.E. (2014). Prolonged preoperative fasting in elective surgical patients: Why should we reduce it? Nutrition in Clinical Practice, 29(1), 22-28.

Pries-Heje, L., \& Dittrich, Y. (2009). ERP implementation as design: Looking at participatory design for means to facilitate knowledge integration. Scandinavian Journal of Information Systems, 21(2), 27-58.

Rasmussen, R., Christensen, A.S., Fjeldsted, T., \& Hertzum, M. (2011). Selecting users for participation in IT projects: Trading a representative sample for advocates and champions? Interacting with Computers, 23(2), 176-187.

Rasmussen, R., Fleron, B., Hertzum, M., \& Simonsen, J. (2010). Balancing tradition and transcendence in the implementation of emergency-department electronic whiteboards. In J. Molka-Danielsen, H.W. Nicolaisen, \& J.S. Persson (Eds.), Selected Papers of the Information Systems Research Seminar in Scandinavia 2010 (pp. 73-87). Trondheim, NO: Tapir Academic Press.

Rogers, E.M. (2003). Diffusion of innovations. Fifth edition. New York: Free Press. 
Sanchez, R., \& Mahoney, J.T. (1996). Modularity, flexibility, and knowledge management in product and organization design. Strategic Management Journal, 17(Winter Special Issue), 63-76.

Schön, D.A. (1963). Champions for radical new inventions. Harvard Business Review, 41(2), 77-86.

Simonsen, J., \& Hertzum, M. (2008). Participative design and the challenges of large-scale systems: Extending the iterative PD approach. In J. Simonsen, T. Robertson, \& D. Hakken (Eds.), PDC2008: Proceedings of the Tenth Anniversary Conference on Participatory Design (pp. 1-10). New York: ACM Press.

Strebler, M., Robinson, D., \& Heron, P. (1997). Getting the best out of your competencies. Brighton, UK: Institute for Employment Studies, University of Sussex.

Topi, H., Karsten, H., Brown, S.A., Carvalho, J.A., Donnellan, B., Shen, J., .. . Thouin, M.F. (2017). MSIS 2016 global competency model for graduate degree programs in information systems. Communications of the AIS, 40, article 18.

Torkilsheyggi, A., \& Hertzum, M. (2017). Incomplete by design: A study of a design-in-use approach to systems implementation. Scandinavian Journal of Information Systems, 29(2), article 2.

Tyre, M.J., \& Orlikowski, W.J. (1994). Windows of opportunity: Temporal patterns of technological adaptation in organizations. Organization Science, 5(1), 98-118.

Winterton, J., Delamare Le Deist, F., \& Stringfellow, E. (2006). Typology of knowledge, skills and competences: Clarification of the concept and prototype. CEDEFOP reference series 64 . Luxembourg: Office for Official Publications of the European Communities.

Woodruffe, C. (1993). What is meant by a competency? Leadership \& Organization Development Journal, 14(1), 29-36. 